\title{
Desemprego de jovens amapaenses com escolarização superior em Macapá e Santana
}

\author{
Unemployment of Young People with Higher Education \\ in Macapá and Santana
}

\author{
Maria Antonia Nascimento Correio* \\ Sandra Regina Smith Correio**
}

\begin{abstract}
Resumo - Este artigo aborda a relação entre precarização do trabalho e desemprego de jovens com escolarização superior nas cidades de Macapá e Santana, no Estado do Amapá, que tem um perfil de economia com alto grau de trabalho informal e forte expansão de trabalhadores com nível superior, certificado por faculdades financiadas pelo ProUni e pelo Fies. A fundamentação teórica salienta a precarização do trabalho, o desemprego no capitalismo contemporâneo e a mercantilização da educação superior no contexto da reestruturação produtiva. A privatização do ensino superior aparece para os jovens que não têm acesso ao ensino público como possibilidade de ascender socialmente. Os resultados da pesquisa indicam que a maioria dos jovens ainda não conseguiu ser inserida no mercado de trabalho no ofício em que foram diplomados e nem em outra atividade que resulte em remuneração qualificada. Os que estão empregados reproduzem as experiências do trabalho precário, vivenciadas antes da conclusão do curso superior.
\end{abstract}

Palavras-chave: desemprego; precarização do trabalho; juventude; escolarização superior.

Abstract - This article discusses the relationship between precarious work and unemployment among young people with higher education in the cities of Macapá and Santana, in the state of Amapá, Brazil, which has an economy profile with high level of informal work and a strong expansion of workers with higher education degrees from institutions funded by ProUni and Fies. The theoretical foundation stresses the precariousness of work, the unemployment rates in contemporary capitalism and the commodification of higher education in the context of productive restructuring. The privatization of higher education appears for young people who do not have access to public education as a possibility to climb the social ladder. The survey results indicate that the majority of young people have not yet been able to

\footnotetext{
"Professora da Faculdade e do Programa de Pós-Graduação em Serviço Social da Universidade Federal do Pará. Correspondência: Rua Augusto Corrêa, 01, Guamá. Belém-PA. CEP: 66075-110. Email: <mariaant@ufpa.br>.

${ }^{* *}$ Assistente Social. Professora do curso de Serviço Social do Instituto Macapaense do Melhor Ensino Superior IMMES. Correspondência: Rua Jovino Dinoá, 2085, Centro. Macapá-AP. CEP: 68900-075 Email: <sandrasmith neves@terra.com.br>.
} 
enter the labor market in the area in which they graduated or in any activities that result in qualified remuneration. Those who are employed resumed the experiences of precarious work from before the completion of the higher course.

Keywords: unemployment; precariousness of work; youth; higher education.

\section{Introdução}

Os efeitos da globalização estão cada vez mais presentes no mundo contemporâneo. Esse processo tem como impacto principal a desregulamentação da força de trabalho, o achatamento de salários, o aumento acentuado do desemprego e do subemprego e, por conseguinte, o aumento da desigualdade social. Dados da Organização Internacional do Trabalho (OIT, 2013a), contidos no Relatório Tendências Mundiais do Emprego em 2013, comprovam que existem, no mundo, 212 milhões de desempregados. Na América do Norte e Europa, em 2012, o índice de desemprego ficou em 8,5\%; na América Latina e no Caribe, em 7,2\%; na Ásia Oriental, incluída a China, 4,1\%; no Sudeste Asiático, 4,7\%; no sul da Ásia, incluindo a Índia, 3,8\%; no Oriente Médio, 10,2\%; no norte da África, 10,9\%; e na África Subsaariana, $8,8 \%$.

O Relatório Tendências Mundiais do Emprego Juvenil da OIT (2013b) demonstra que o desemprego entre os jovens cresce de forma preocupante, tendo atingido, em 2013, a taxa de 13,1\%, algo em torno de 74,5 milhões de jovens desempregados no mundo. $\mathrm{O}$ documento atesta que a prolongada crise mundial agrava o desemprego juvenil e dificulta o acesso ao emprego para os jovens, obrigando-os a serem menos seletivos com os empregos e a aceitarem trabalhos temporários e em tempo parcial.

No mundo, ainda segundo o relatório, $15,8 \%$ dos jovens não trabalham nem estudam, situação de $19,85 \%$ dos jovens na América Latina e no Caribe. Registra-se, também em 2012, que 17,7 milhões de jovens de 17 dos 20 países do G20 estão sem emprego. Itália, Espanha e África do Sul aparecem com taxas entre 35\% e 52\% de jovens sem emprego. Argentina, Brasil, Canadá, Estados Unidos, Rússia e Turquia apresentam taxas entre $15 \%$ e $18 \%$ (OIT, 2013).

No Brasil, dados do MDS/IBGE mostravam que, em 2012, a taxa de desemprego era de 6,1\% e, em 2013, de 5,5\%. Em 2012, já havia 6,2 milhões de pessoas desempregadas no Brasil, mas a taxa de desemprego entre os jovens era duas vezes maior, 12,5\%, e, em 2013, 14\%. Ainda segundo a fonte, o índice de desemprego melhorou entre a população em geral, mas os jovens tinham três vezes mais chances de ficar desempregados 


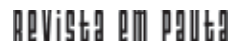

\} DESEMPREGO DE JOVENS AMAPAENSES - CORREIO, M. A. N.; CORREIO, S. R. S. \}

DOI: $10.12957 /$ REP.2016.27865

(MDS, 2012). A OIT (2013), ao discriminar o índice de desemprego da população jovem no Brasil, salientava a diversificação entre as regiões do país. A média nacional estava em torno de 17,8\%, mas no estado do Amapá chegava a $32,1 \%$ e, em Santa Catarina, a $8,5 \%$.

A OIT (2013) mostra ainda que, no Amapá, a taxa de desemprego entre a população total ficou em $11,7 \%$, em 2012, e entre os jovens, em torno de $27 \%$. Este dado é maior que a média nacional, que está em 13,2\%. Ainda de acordo com os dados do MDS/IBGE (2012), metade da população residente em 17 capitais brasileiras não chegava a receber o valor de um salário mínimo. Entre as que apresentaram dados mais graves, destaca-se a cidade de Macapá, que possui rendimento médio domiciliar per capita de $\mathrm{R} \$ 631,00$, com 50\% da população recebendo até R\$316,00.

Diante da realidade de desemprego em geral, principalmente entre os jovens no Brasil, nos últimos 11 anos emergiram políticas públicas de caráter social, focalizadas na população considerada em situação de extrema pobreza, por meio de programas de transferência de renda, tais como o "Bolsa Família", "Minha Casa, Minha Vida", "Programa Luz para Todos", e os programas educacionais direcionados ao acesso de jovens pobres ao ensino superior, entre os quais se destacam o Programa Universidade para Todos (ProUni) e o Fundo de Financiamento Estudantil (Fies).

O ProUni é um programa do Ministério da Educação e Cultura (MEC) que concede bolsas de estudo, integrais e parciais, em instituições privadas. A seleção é efetuada por meio da nota do Exame Nacional do Ensino Médio (Enem). As bolsas integrais do ProUni são destinadas a estudantes cuja renda mensal bruta é de até um salário mínimo e meio, e as parciais, com redução de $50 \%$ no valor das mensalidades, a estudantes com renda mensal bruta de até três salários mínimos. Os candidatos devem, obrigatoriamente, ter cursado o ensino médio em escola pública ou ter sido bolsista em escola privada. Pessoas com deficiência também podem ser beneficiadas.

O ProUni é responsável pelo fortalecimento de um modelo de educação superior que prioriza o superlucro, em detrimento do ensino de qualidade. Funcionando por meio de incentivos fiscais às instituições de ensino privado, esse programa pode ter sido responsável pela transformação de pequenas faculdades em grandes grupos empresariais de educação, que comercializam suas ações na Bolsa de Valores (BORGES, 2009).

Desde a sua implantação em 2005 até 2012, o número de bolsas do ProUni aumentou em 82,25\%. No início, em 2005, eram 112.275 bolsas e, em 2012, já eram 204.622 bolsas parciais e integrais. Segundo dados do Sistema do ProUni (SISProUni), de 2005 até o $1^{\circ}$ semestre de 2013 foi oferecido um total de 1.217.179 bolsas. Dessas, o número de 782.124 bolsas $(74 \%$ do total) foi para estudantes de cursos no período noturno. Trata-se, em sua maioria, de bolsas integrais, somando $64 \%$ no primeiro semestre de funcionamento, em 2005, e mantendo-se no percentual de $67 \%$ no primeiro semestre de 2013 . Cabe ressaltar que as bolsas integrais 


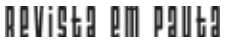

\} DESEMPREGO DE JOVENS AMAPAENSES - CORREIO, M. A. N.; CORREIO, S. R. S. \}

DOI: $10.12957 /$ REP.2016.27865

cobrem $100 \%$ do valor das mensalidades dos cursos particulares, e as parciais cobrem de $25 \%$ a $50 \%$. Uma informação relevante é que, no primeiro semestre de 2013,13\% das bolsas foram destinadas a alunos dos cursos superiores na modalidade EaD (educação a distância) (BORGES, 2009).

O Fies é um financiamento operado pelo Fundo Nacional de Desenvolvimento da Educação (FNDE), que estabelece juros de 3,4\% ao ano. $\mathrm{O}$ estudante pode solicitar o financiamento em qualquer época do ano, e o pagamento corre após dezoito meses de carência. Em seguida ao período de carência, inicia-se o pagamento do financiamento, cujo saldo devedor poderá ser pago em até três vezes o período do curso, o que pode levar até treze anos.

É preciso considerar que, apesar de os juros serem baixos, o financiamento tem proporcionado um aumento abusivo do valor das mensalidades, já que o recebimento da mensalidade é garantido. Dessa forma, depois de formado e com poucas possibilidades de inserção no mercado de trabalho, o indivíduo tem que arcar com o pagamento da dívida e, sem emprego, apela para qualquer trabalho que lhe garanta renda para a sua sobrevivência. O Censo da Educação Superior (INEP, 2013), que estabelece a relação entre as matrículas nas instituições privadas e universidades públicas, por unidades da federação, no ano de 2013, indicava que o Estado do Amapá se encontrava em $12^{\circ}$ lugar, apresentando uma taxa de 2,04 estudantes nas universidades públicas para cada aluno nas instituições privadas. Grande parte da implantação dessas faculdades ocorreu nos últimos dez anos.

Tendo em vista os dados referidos, este estudo tem como objetivos refletir sobre a relação entre a precarização do trabalho e o desemprego entre os jovens com nível de escolarização superior nas cidades de Macapá e Santana. Visa, assim, contribuir, por meio de reflexões críticas, para a redefinição das políticas sociais, que estimulem, sobretudo, as lutas pela expansão da educação pública de qualidade.

O texto baseia-se em dados e inferências elaborados no âmbito da redação de uma tese de doutoramento, defendida junto ao Programa de Pós-Graduação em Sociologia, da Universidade Federal do Pará (UFPA). O procedimento teórico-metodológico, de legado marxista, orienta-se pelas mediações que se colocam entre a universalidade da acumulação do capital, a particularidade da realidade socioeconômica do Brasil e a singularidade do subemprego e desemprego nas cidades de Macapá e Santana, no estado do Amapá, no contexto atual.

Os procedimentos técnicos operativos levaram em conta a observação nos locais de moradia e de trabalho, a aplicação de formulários socioeconômicos e a realização de entrevistas semiestruturadas com vinte jovens na faixa etária de 22 a 29 anos, de ambos os sexos, sendo onze mulheres e nove homens. Os entrevistados concluíram o curso de formação 


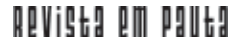

\} DESEMPREGO DE JOVENS AMAPAENSES - CORREIO, M. A. N.; CORREIO, S. R. S. \}

DOI: $10.12957 /$ REP.2016.27865

universitária em regime presencial, em faculdades privadas, com, no mínimo, quatro anos de duração, devidamente reconhecidos pelo MEC.

A amostra foi constituída de forma a garantir a representatividade das diversas situações nas quais se encontram os jovens: aqueles que vivenciam formas de precarização do trabalho, os que perderam o emprego e não conseguiram uma nova colocação no mercado de trabalho e os que nunca tiveram acesso a um emprego. Os entrevistados tinham entre um e sete anos de formados.

Os resultados e a discussão da pesquisa estão organizados em três partes. Na primeira, apresenta-se uma síntese do processo de reestruturação capitalista, que se manifesta na precarização exacerbada do trabalho e no desemprego estrutural; na segunda, discorre-se sobre o processo de reestruturação das universidades no contexto da reestruturação produtiva; na terceira, apresenta-se a análise dos dados sobre o desemprego e precarização do trabalho juvenil nas cidades de Macapá e Santana, visando apreender a sua singularidade na sociedade amapaense.

\section{Precarização do trabalho e desemprego no capitalismo contemporâneo}

As metamorfoses ocorridas no âmbito do sistema de produção capitalista nos anos 1970 imprimiram transformações importantes nos processos e nas condições de trabalho de milhares de trabalhadores em todo o mundo. Primeiramente, foram atingidas as economias centrais, invadindose, posteriormente, os países periféricos, o que produziu um cenário onde convivem a acumulação e a concentração da riqueza, com a ampliação do desemprego, a precarização do trabalho e o agravamento da pobreza.

O processo de reestruturação capitalista é visto como uma estratégia para enfrentar a crise do capital que se abateu sobre o mundo, de forma mais intensa na década de 1970. Essa ação levou o capital a dar respostas à sua própria crise, iniciando um perverso movimento de reorganização de seu sistema ideológico e político de dominação, tendo como principal aliado o projeto neoliberal, responsável pela privatização do Estado, a diminuição exacerbada dos direitos sociais, fruto das lutas políticas da classe trabalhadora, e a desregulamentação dos direitos do trabalho. O processo, que se apoia no avanço tecnológico e na constituição da acumulação flexível, afetou fortemente o mundo do trabalho e a classe trabalhadora.

Trata-se de um modelo de acumulação que implica a perda dos direitos sociais da classe trabalhadora, mudança na concepção de cidadania, aprofundamento da distância entre público e privado, evolução da legislação trabalhista para a mercantilização das relações e, portanto, desproteção da força de trabalho, reduzindo a atuação do Estado ao assistencialismo seletivo. 


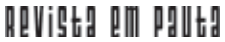

\} DESEMPREGO DE JOVENS AMAPAENSES - CORREIO, M. A. N.; CORREIO, S. R. S. \}

DOI: $10.12957 /$ REP.2016.27865

A reestruturação produtiva e as políticas neoliberais, de acordo com Druck (2002), eram uma resposta à crise estrutural do capital, na tentativa de instituir um novo padrão de gestão do trabalho e de Estado que substituísse o fordismo. Quando a referência é o emprego fordista, nota-se que não está apenas relacionado ao trabalho na fábrica, pois esse sistema de produção passou a se constituir como um modo de vida que se espraia pelas várias instâncias da vida social e invade as inúmeras formas de trabalho na indústria, no comércio, na prestação de serviços e no serviço público.

A resposta baseada na acumulação flexível, além de não promover a superação do fordismo, aprofundou a crise e combinou novas tecnologias e padrões flexíveis com formas tipicamente fordistas. Há, em âmbito global, um processo intenso de flexibilização do trabalho, que se manifesta na subcontratação, no emprego temporário, em atividades autônomas, na informalidade, nas cooperativas de trabalho e outras formas de trabalho assalariado disfarçado.

O avanço tecnológico representa o próprio triunfo do capitalismo, que se expressa pela denominada terceira revolução tecnológica. Esse triunfo foi traduzido por uma ampliação da oferta de mercadorias, beneficiando a quem pode pagar e reduzindo o progresso à lógica consumista. Para o capitalismo, os frutos da tecnologia não necessitam ser compartilhados com toda a população, mas ser postos a serviço do capital e da elite dominante, servindo como mais um instrumento de dominação.

Para os trabalhadores, entendidos aqui no sentido adotado por Antunes (2000), que define essa classe a partir da totalidade dos assalariados (homens e mulheres que vivem da venda de sua força de trabalho, incluindo o proletariado moderno, fabril e de serviços, os servidores públicos, o proletariado precarizado, com trabalhos temporários, e a totalidade dos desempregados), a reestruturação produtiva traz consequências destrutivas; entre elas, a barbárie do mundo contemporâneo: o desemprego estrutural. Nesse sentido, as formas precárias de inserção no mundo do trabalho passam a ser dominantes em muitas regiões do mundo, sendo responsável pelo aumento do trabalho informal.

Sobre a informalidade, Antunes (2013) define o que denomina de "formas de ser da informalidade". Este conceito relaciona-se aos trabaIhadores informais tradicionais, representados por aqueles que, por meio da atividade, tentam garantir renda para a sua sobrevivência e de sua família. Não há horário fixo de trabalho e as jornadas levam frequentemente ao uso das horas vagas para aumentar a renda. Neste grupo encontram-se aqueles que executam atividades informais em períodos de desemprego, enquanto aguardam outra oportunidade de inserção no mercado de trabalho (ANTUNES, 2013, p. 16).

A informalização da força de trabalho vem se constituindo como o principal mecanismo utilizado pela engenharia do capital para ampliar a intensificação dos ritmos e dos movimentos do trabalho e também o seu 


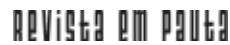

\} DESEMPREGO DE JOVENS AMAPAENSES - CORREIO, M. A. N.; CORREIO, S. R. S. \}

DOI: $10.12957 /$ REP.2016.27865

processo de valorização. E, ao fazê-lo, desencadeia um importante elemento propulsor da precarização estrutural do trabalho.

Cabe aqui uma consideração importante. Uma vez que o capital articula inúmeras formas de produção no próprio modo de produção capitalista, sendo a relação entre trabalho formal e informal uma criação do próprio capital, o trabalho informal só pode ser explicado a partir da acumulação e da dinâmica capitalista.

Antunes (2006) reforça que a queda da taxa de lucro, em decorrência do aumento do valor da força de trabalho e do desenvolvimento das lutas sociais nos anos 1960, entre outras causas, constitui-se como um aspecto evidente da presente crise do capital, que teve início nos anos 1970. Para o autor, a "conjugação destes elementos levou a uma redução dos níveis de produtividade do capital, acentuando a tendência decrescente da taxa de lucro" (ANTUNES, 2006, p. 29). Ele cita, ainda, outros fatos que indicavam um quadro de crise, entre estes o esgotamento do padrão taylorista/fordista de acumulação, a hipertrofia da esfera financeira, a maior concentração de capitais, a crise do Estado de Bem-Estar Social e o incremento acentuado das privatizações.

A partir da década de 1980, a substituição do trabalho vivo pelo trabalho morto tem atingido proporções inéditas na história do modo de produção capitalista. Pode-se dizer que, no Brasil, o processo de reestruturação produtiva inicia-se nos anos 1980 , com a introdução de novas formas de gestão no mundo do trabalho, ainda restritas, nesse período, a empresas multinacionais.

Segundo Antunes (2013, p. 16), as primeiras iniciativas de reestruturação produtiva estavam relacionadas à adoção de novos padrões organizacionais e tecnológicos baseados nos programas de qualidade total. Surgem os Círculos de Controle de Qualidade (CCQ), que "são instaurados não apenas como componentes da 'modernização produtiva', mas, principalmente, como um novo recurso de controle do trabalho" (ALVES, 2010, p. 127).

É somente nos anos 1990 que a economia brasileira vai passar por transformações significativas que, aliadas ao projeto neoliberal, imprimem mudanças no mundo do trabalho. Essa reestruturação produtiva ganha força nos governos Fernando Collor de Melo e Fernando Henrique Cardoso. As mudanças decorrentes desse processo são responsáveis pela ampliação do desemprego no país, no período em que se verifica um aumento dos postos de trabalho, porém, sem garantia de direitos trabalhistas, o que implica o aumento da precarização do trabalho.

Dessa forma, o processo de reestruturação produtiva implantado no Brasil a partir dos anos 1980 se solidifica nos anos 1990, tendo por base a terceirização. A imposição de processos ágeis de produção e de trabalho exige cooptar trabalhadores que se submetam a condições de trabalho adversas. 
A respeito da terceirização, Thébaud-Mony e Druck (2007) salientam que esse fenômeno se generalizou no mundo e abrange todas as atividades da indústria, comércio, serviços e dos setores público e privado. No Brasil, a terceirização é utilizada como principal estratégia do processo de reestruturação produtiva, principalmente relacionada à flexibilização dos contratos de trabalho.

O mercado de trabalho caracterizado pela exacerbação da precariedade mantém-se pelo uso da força de trabalho mais vulnerável: mulheres, negros, jovens, migrantes e imigrantes. Essa questão não tem caráter social, mas de submissão, uma vez que esses trabalhadores não estão protegidos contra o desemprego, mesmo quando possuem altos níveis de escolaridade, com vivência familiar considerada estruturada, como é o caso dos jovens amapaenses.

\section{Reestruturação produtiva e mercantilização da educação superior}

A reestruturação do ensino superior, consequência da reestruturação produtiva que se alastrou sobre as economias capitalistas, não é um fenômeno específico do Brasil, mas uma realidade presente em todos os países, ainda que de formas e graus de desenvolvimento diferenciados: "Trata-se de um fenômeno que acompanha as transformações na base econômica dos diferentes países, onde a crise do fordismo e do Estado de Bem-Estar se fazem sentir nos anos 60 e 70" (SILVA JR.; SGUISSARDI, 2001, p. 25).

No Brasil, a expansão acelerada da educação superior só ocorreu a partir dos anos 1990. Esse processo tem visibilidade no contexto da implantação do projeto neoliberal no país e tem como principais características a privatização e precarização do setor público, e a ampliação do setor privado.

Foi um período marcado pela Reforma do Aparelho do Estado promovida pelo governo de Fernando Henrique Cardoso e coordenada pelo então Ministro da Administração Federal e Reforma do Estado, Bresser Pereira. Para ele, no Brasil e na América Latina, a crise do Estado era definida como uma crise fiscal nos anos 1980, "acirrada pela crise da dívida externa, e pela prática do populismo econômico" (BEHRING, 2003, p. 172).

O Plano Diretor de Reforma do Estado, publicado em 1995 pelo Ministério de Administração e Reforma do Estado (Mare), apresentava os objetivos e principais diretrizes para a reforma do Estado brasileiro e afirmava que a crise do Estado no Brasil se inicia nos anos 1970, mas só se torna visível nos anos 1980. Dessa forma, além da crise fiscal, vários países passaram a apresentar diminuição das taxas de crescimento econômico, além do aumento da inflação e do desemprego. O referido plano asseverava que a desaceleração econômica nos países desenvolvidos e os desequilíbrios 


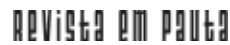

\} DESEMPREGO DE JOVENS AMAPAENSES - CORREIO, M. A. N.; CORREIO, S. R. S. \}

DOI: $10.12957 /$ REP.2016.27865

na América Latina eram a causa da crise do Estado, que não soubera processar de forma adequada a sobrecarga de demandas a ele dirigidas.

O processo de adequação do Brasil ao capitalismo contemporâneo promoveu um desmonte do Estado brasileiro, com desdobramentos significativos no mundo do trabalho. Segundo Chauí (2001), os fundamentos dessa reforma são claros: todos os problemas do Estado brasileiro estão relacionados a um provável desvio da sua missão principal, por ter passado a atuar na esfera produtiva para o mercado, em serviços não exclusivos. Nesse sentido, a reforma prevê a redução do papel do Estado como prestador direto de serviços públicos, inclusive na educação e na saúde, à medida que "exclui as exigências democráticas dos cidadãos ao seu Estado, e aceita apenas as exigências feitas pelo capital" (CHAUÍ, 2001, p. 176). O processo de exclusão das conquistas econômicas, sociais e políticas, fruto das lutas dos trabalhadores, gera uma mudança radical, substituindo o conceito de direitos pelo de serviços, que devem ser adquiridos no mercado. Ainda segundo Chauí (2001, p. 177), a "Reforma reduz o espaço público dos direitos e aumenta o privado inclusive no campo dos diretos sociais conquistados".

Nesse sentido, no final do século XX, o projeto neoliberal implantado em diversos países da América Latina foi responsável pela promoção, por parte dos governos, de uma profunda reestruturação dos sistemas nacionais de educação. Estabeleceu-se uma série de medidas provenientes desse processo, como a redução dos recursos públicos direcionados ao financiamento da educação, à diminuição dos investimentos em infraestrutura e dos gastos com professores e demais servidores das universidades.

Pablo Gentili (2001, p. 99) fala de uma profunda redefinição do papel do Estado do ponto de vista educacional, com o abandono do Estadodocente substituído por um Estado-avaliador que, distante da função de educar, inclinou-se a se assumir como agência fiscalizadora, determinando os graus de eficácia, eficiência e produtividade das instituições educativas.

A reforma da educação superior no contexto da reforma do Estado teve por princípio a suposição de que a crise na educação superior seria responsável pela não absorção de toda a demanda e pelo preparo inadequado dos estudantes para a inserção no mercado de trabalho. A causa desse processo estaria relacionada ao modelo das universidades brasileiras, voltadas para a pesquisa que, pelo seu alto custo, seria insustentável ao poder público em momentos de crise, e para a elitização, que faria parte do processo de construção das universidades brasileiras (SILVA JR.; SGUISSARDI, 2001).

Parece claro, no processo de reforma do Estado, que o objetivo era incorporar a educação superior ao mercado, reduzindo a esfera pública e constituindo a educação como mercadoria, o que possibilita a garantia do superlucro, objeto principal do capitalismo. O novo ciclo de expansão da educação superior no país se estabelece, assim, por meio de grandes grupos empresariais, cuja capacidade financeira está direcionada à con- 


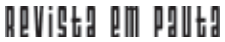

\} DESEMPREGO DE JOVENS AMAPAENSES - CORREIO, M. A. N.; CORREIO, S. R. S. \}

DOI: $10.12957 /$ REP.2016.27865

quista de espaço no mercado, representando a possibilidade de investimento para o capital financeiro mundializado. Esse processo de entrada da iniciativa privada no setor educacional superior foi ainda impulsionado pela aprovação da Lei de Diretrizes e Bases da Educação (LDB), Lei n. 9394 de 12 de dezembro de 1996.

O que se observa é a constante privatização interna das universidades, por meio da captação de recursos externos compensatórios, "decorrentes da erosão salarial e da queda no financiamento da pesquisa pelas agências governamentais" (TRINDADE, 2001, p. 20). A precarização e privatização do espaço público são resultantes de um processo de reestruturação das universidades. Esse processo se evidencia na diminuição de recursos para financiamento da educação, em um conjunto de leis e medidas que alteram a sua base normativa e em uma redefinição do papel do Estado no que se refere à educação pública e privada. Criam-se várias formas de adequação das universidades aos ditames do mercado, incentivando a privatização da formação de nível superior e desvirtuando a missão pública dessas instituições.

A missão pública da universidade diz respeito à formação da cidadania, à produção e difusão de conhecimento e se contrapõe à universidade construída de acordo com a lógica orientada para a satisfação das necessidades do mercado. Os estudantes transformam-se em clientes e a educação passa a pertencer à esfera dos interesses privados. Nessa lógica, cada indivíduo deve efetuar o seu próprio investimento para ter acesso à mercadoria "educação superior".

A expansão das políticas neoliberais que invadem as universidades por meio da reforma do Estado trouxe consigo a redução do financiamento das universidades públicas e o aumento exacerbado das universidades privadas, transformando o investimento em educação superior privada em um dos mais rentáveis do país, colocando o Brasil entre os primeiros lugares no que respeita à privatização do ensino superior (GENTILI, 2001).

Chauí (2001) afirma que, no Brasil, a educação superior é um privilégio das elites e não um direito de todos. Para a autora, a reforma efetuou o desmonte de um patrimônio público de qualidade. Aos filhos das famílias pertencentes aos estratos inferiores da classe média resta um ensino fundamental e médio deficiente ou o abandono da escola, entrando de forma imediata no mercado de trabalho de forma precarizada.

Trata-se de processo que pode lhes tirar a possibilidade de enfrentar vestibulares em universidades públicas, obrigando-os a desistir ou a recorrer a instituições privadas de educação superior, que oferecem um ensino de baixa qualidade e têm por princípio o lucro. Dessa forma, o maior número de vagas nas universidades públicas é destinado aos filhos da classe média, alta e burguesa, formados em escolas particulares de qualidade e, por isso, com melhores condições de acesso à universidade pública e gratuita. 
Santos (2011) assegura que, no momento em que o Estado toma a decisão de diminuir o seu compromisso político com a educação superior, provoca uma crise sem precedentes nas universidades, obrigando as instituições públicas a competir no emergente mercado de serviços universitários: "Com a transformação da universidade num serviço a que se tem acesso, não por via da cidadania, mas por via do consumo e, portanto, mediante pagamento, o direito à educação sofreu uma erosão radical" (SANTOS, 2011, p. 27).

Assim, transformam-se estudantes em cidadãos consumidores, por meio da diminuição da gratuidade no ensino universitário e pela substituição de bolsas de estudos por empréstimos, como é o caso do Fies.

Dados do Censo da Educação Superior (2013) chamam a atenção para a evolução das matrículas na educação superior no período de 1980 a 2013, sobretudo para a relação entre o número de matrículas nas universidades públicas e privadas. Constata-se que, ao longo de 33 anos, houve um aumento de $26 \%$ nas matrículas em universidades públicas, e de $74 \%$ nas instituições privadas. $O$ processo de expansão da educação superior particular intensifica-se a partir dos anos 1990, e vem crescendo de forma progressiva em um percentual muito maior que o das matrículas nas universidades públicas.

Leher (2001) afirma que, desde meados de 1980, o Banco Mundial defende que o ensino elementar é o que oferece melhor taxa de retorno econômico e político. Segundo ele, trata-se da criação do novo espírito capitalista e a difusão da ideologia de que o emprego futuro depende da formação e empregabilidade obtidas no sistema educacional pelos indivíduos.

Bourdieu (2007), na década de 1970, já defendera a ideologia da educação como mecanismo de mobilidade social. Ele afirmava ser o sistema escolar um dos principais mecanismos de conservação social, "pois fornece a aparência de legitimidade às desigualdades sociais, e sanciona a herança cultural e o dom social tratado como dom natural" (BOURDIEU, 2007, p. 41). Nesta direção, Pochmann (2006) alerta para as diferenças existentes em relação à educação e trabalho entre ricos e pobres, uma vez que há reprodução da desigualdade no interior do mercado de trabalho.

\section{Precarização do trabalho e desemprego: o impacto sobre os jovens trabalhadores com escolarização superior nas cidades de Macapá e Santana}

A sociologia da juventude tem relativizado a definição de jovem, remetendo a discussão sobre a juventude ao âmbito do imbricamento das relações sociais de classe, gênero, raça/etnia, geração e interterritorialidade. No Brasil, a dimensão geracional ou etária tem como referência a 


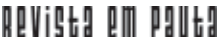

\} DESEMPREGO DE JOVENS AMAPAENSES - CORREIO, M. A. N.; CORREIO, S. R. S. \}

DOI: $10.12957 /$ REP.2016.27865

Organização das Nações Unidas (ONU), para a qual a juventude é a fase da vida do indivíduo que vai dos 15 aos 24 anos (CORTI; SOUZA, 2004, p. 11). Por outro lado, a Constituição Federal Brasileira de 1988 designa como adolescentes as pessoas entre a faixa etária de 12 a 18 anos (BRASIL, 1988), o que deixa de fora parte da população considerada jovem.

A aprovação da Lei n. 12.852 de 5 de agosto de 2013 institui o Estatuto da Juventude e garante os diretos dos jovens, considerando-os pessoas na faixa etária entre 15 e 29 anos (BRASIL, 2013). A pesquisa que gerou este artigo compreendeu a categoria juventude a partir da faixa etária entre 15 e 29 anos, mas, para além dos marcadores etários, considerou-se que essa categoria é permeada pelas relações de gênero, classe, geração, raça/etnia, entre outras dimensões que afetam a vida das pessoas em geral e dos jovens em particular.

Abramo (2008) salienta que a percepção da juventude, para além do risco social e dos setores da classe média, é recente no país. Entre os debates que se evidenciam na atualidade, é possível citar o que se apoia nas possibilidades de os jovens participarem do processo de conservação, mas também transformação da sociedade. Outro debate focaliza a juventude a partir das condições de inclusão e exclusão social. Um terceiro debate prioriza o exame da singularidade da condição juvenil sob a ótica dos direitos de que este segmento é destinatário. Para a mesma autora, essas concepções não são excludentes, mas se complementam e mostram caminhos para o conhecimento da condição juvenil no país.

Frigotto (2004) confirma a dificuldade de se ter um único conceito de juventude. Essa dificuldade, segundo o autor, está associada a questões de ordem histórica, social e cultural. Para ele, o mais apropriado seria a utilização do termo "juventudes", principalmente quando utilizarmos o recorte de classe. As transformações contemporâneas operam mudanças estruturais nos padrões e nos modos de vida, incidindo sobre os jovens. Martín-Barbero (2008), ao chamar a atenção para a relação entre juventude e educação, afirma que o ensino médio e universitário demonstra a clara incapacidade de garantir uma formação científica, havendo uma desvalorização dos diplomas na hora de procurar emprego e uma ressignificação da escolarização, que se tornou secundária.

As cidades de Macapá e Santana', no estado do Amapá, espaço geográfico onde se efetivou a pesquisa empírica, são típicas cidades da Amazônia, cujo modelo de desenvolvimento pauta-se na lógica do sistema capitalista globalizado, neodesenvolvimentista e socialmente excludente. Situadas na foz do Amazonas, suas economias são marcadas pela alta pro-

\footnotetext{
1 A capital do estado, Macapá, localiza-se no extremo norte do país. É a única capital brasileira banhada pelo Rio Amazonas, com 446.757 habitantes (IBGE, 2014). Sua expansão demográfica consolida-se pelo crescimento acentuado do processo migratório e do êxodo rural. A cidade de Santana, no período de 1991 a 2000, apresentou uma taxa geométrica de crescimento populacional de 5,14\%, e de urbanização de $94,55 \%$.
} 


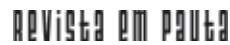

\} DESEMPREGO DE JOVENS AMAPAENSES - CORREIO, M. A. N.; CORREIO, S. R. S. \}

DOI: $10.12957 /$ REP.2016.27865

porção da informalidade, forte participação do setor de serviços e comércio no PIB e, por outro lado, uma forte expansão do ensino superior.

Segundo dados do Censo da Educação Superior, em 2013, a capital do Amapá possuía 25 instituições de ensino superior registradas no Ministério da Educação (MEC), que ofereciam 102 cursos com ensino presencial, e 15 instituições de nível superior que ofertam 73 cursos com sistema de ensino a distância. Destas, somente três eram públicas, sendo uma federal e outra estadual, e um instituto federal. Das instituições privadas, apenas duas estavam formalizadas como universidades, as outras, em um total de 23, estavam estruturadas como faculdades. Grande parte da implantação dessas faculdades ocorreu nos últimos 10 anos. A maioria dos jovens entrevistados habilitados no setor privado recebeu financiamento do Fies.

Os cursos ofertados pelas universidades públicas em Macapá e Santana são: Administração, Arquitetura, Bacharelado em Direito, Enfermagem, Licenciatura em História, Educação Física, Letras e Pedagogia. No caso das universidades privadas, além de Administração, Pedagogia e Direito, ofertava-se Administração Socioambiental, Redes de Computadores, Serviço Social, Turismo, Relações Públicas e Fisioterapia. A amostra da pesquisa contemplou egressos de todos os cursos ofertados, porém, observou-se que a oferta não tinha relação direta com a demanda do mercado local.

Macapá e Santana possuem uma economia incipiente, com pouca diversificação e mercado de trabalho em formação, mas dois processos estão visivelmente presentes: o setor de serviços e o setor público. Em Macapá, segundo Nascimento, Neves, Baracho (2015, p 160), o mercado de trabalho formal totalizava 88.053 postos em $2010,46,5 \%$ a mais em relação a 2004. O desempenho do município ficou abaixo da média verificada para o estado, que cresceu 54,3\% no mesmo período. Em 2010, a administração pública foi o setor que apresentou maior volume de empregos formais, com 39.882 postos de trabalho, seguido do setor de serviços, com 22.522 postos. Somados, os dois setores representavam $70,9 \%$ do total de empregos formais do município.

Os dados mostram que a estrutura econômica do município de Macapá demonstra participação expressiva do setor de serviços, o que corresponde a $84 \%$ do Produto Interno Bruto (PIB municipal). O setor de serviços gera uma grande demanda para o mercado de trabalho, mas essa demanda atinge poucos trabalhadores com nível de escolarização superior, pela própria composição do setor.

A cidade de Santana também experimenta um aumento expressivo do setor de serviços, que corresponde a 74\% do PIB municipal. Vale ressaltar que $19 \%$ da composição do PIB diz respeito ao setor secundário ou industrial, que cresceu acima da média do próprio Amapá. Esse processo está relacionado à implantação, na cidade, de mineradoras que exploram o manganês, e ao grande capital internacional que explora minério na região do Amapá, com sede em Santana. 


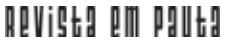

\} DESEMPREGO DE JOVENS AMAPAENSES - CORREIO, M. A. N.; CORREIO, S. R. S. \}

DOI: $10.12957 /$ REP.2016.27865

O setor público ainda é o que mais absorve trabalhadores com ensino superior por meio de concursos e de contratos precários de trabalho, como o contrato administrativo. Nesse contexto, os egressos dos cursos de Serviço Social, Enfermagem, Pedagogia, Fisioterapia, Educação Física e Licenciaturas podem ser mais facilmente absorvidos pelo setor público, pela necessidade de inclusão desses profissionais nas diversas políticas públicas executadas pelo Estado. Todavia, as vagas que surgiam eram insuficientes para atender à demanda.

Nessas cidades, portanto, o mercado de trabalho estrutura-se de modo incipiente e heterogêneo, influenciado por uma intensa migração do interior para a cidade, de outras cidades da Amazônia e também de diversas unidades da federação. Neste último caso, destaca-se a migração de jovens com elevada qualificação, aprovados em concursos públicos, que se estabeleceram em Macapá e Santana. Em consequência, grande parte dos trabalhadores locais com escolarização superior encontra-se em ocupações informais e está sujeita à baixa remuneração e precarização das relações de trabalho.

Dos entrevistados, apenas uma jovem trabalhava como assistente social no governo do Estado, exercendo cargo comissionado; dez encontravam-se desempregados e nove exerciam atividades remuneradas que não correspondiam à sua formação em nível superior.

Nos depoimentos dos jovens entrevistados ficou evidente que a incorporação do discurso que considera a educação como solução para o desemprego e possibilidade segura de mobilidade social foi fundamental para o investimento das famílias na formação superior, principalmente em instituições privadas. A falta de oportunidades fazia parte do cotidiano desses jovens, cuja trajetória ocupacional estava permeada pela precariedade e informalidade. Um ponto comum entre os informantes era a percepção de uma grande pressão por parte da família para que "dessem retorno", especialmente financeiro, já que precisavam quitar a dívida com o Fies.

Todos os entrevistados informaram que os pais se esforçaram ao máximo, almejando proporcionar-lhes maior escolarização e inserção mais qualificada no mercado de trabalho. Todavia, ocorreu o inverso e a frustração era sentida de forma pungente pelos jovens. Por outro lado, comumente os pais possuíam menor escolaridade. E, não obstante, na década de 1980, conseguiram melhores colocações no mercado de trabalho, principalmente os funcionários públicos. Os jovens, apesar do avanço nos estudos, em alguns casos, ocupavam posições no mercado de trabalho inferiores às de seus pais, caracterizadas pela precarização e informalidade. Outros sofriam preconceito pela situação de desempregado e, portanto, demonstravam angústia e vergonha. Esses traços foram marcantes nas falas dos jovens entrevistados.

Ainda segundo os relatos, a expectativa de que a realização de um curso superior poderia diminuir o caminho para o mercado de trabalho 


\section{hevistg aाm pguttg}

\} DESEMPREGO DE JOVENS AMAPAENSES - CORREIO, M. A. N.; CORREIO, S. R. S. \}

DOI: $10.12957 /$ REP.2016.27865

se dilui quando os jovens diplomados se deparam com a realidade: os cursos em que foram habilitados, em sua maioria, não respondem às demandas do mercado, mas sim à possibilidade de transformar a educação em mercadoria para ser vendida no mercado da educação, como Administração Socioambiental, que, segundo os entrevistados, habilitava muitos jovens em Macapá e Santana.

Durante o período de realização da pesquisa, os jovens empregados vivenciavam as mesmas experiências de trabalho precário que desenvolviam antes da formação profissional, tais como taxista, manicure, consertos em domicílio, venda de confecções, venda de artesanato, venda de bolos e doces caseiros, situação que gerava frustração e incerteza quanto ao futuro profissional.

A referência ao medo do desemprego foi recorrente entre os entrevistados, o que os deixava fragilizados e vulneráveis. Tratava-se do receio de não encontrar trabalho ou de perder o emprego, mesmo que precário ou exigindo menor escolaridade. Há, também, o medo de não conseguir sustentar a família, de fracassar, de não poder planejar o futuro. Esse sentimento pode estar relacionado ao confronto entre a história individual repleta de sonhos, projetos e desejos e a forma como estavam experimentando a organização do mundo do trabalho, prevalecendo ocupações temporárias, precárias e na informalidade.

Desse modo, a condição de excluído, em suas várias dimensões e formas de expressão, provocava sofrimento psíquico, fragmentação da relação do jovem com a família e amigos, além da perda do sentimento de pertença. E, sendo assim, reafirma-se o que foi apontado por um estudioso da questão: "os excluídos não são simplesmente rejeitados física, geográfica ou materialmente, não apenas do mercado de trocas, mas de todas as riquezas espirituais, seus valores não são reconhecidos, ou seja, há também uma exclusão cultural" (WANDERLEY, 2006, p. 16).

Tem-se, de certo modo, um paradoxo. O ingresso na faculdade tornou-se mais acessível aos jovens amapaenses, em um contexto no qual possuir diploma superior era, há pouco mais de duas décadas, relativamente raro e restrito aos que tinham condições financeiras de pagar para estudar em outro estado ou em outra cidade, preferencialmente em Belém do Pará, ou àqueles que conseguiam ter acesso a algum subsídio originado das políticas públicas educacionais, como bolsas, crédito subsidiado ou auxíliohospedagem.

Contudo, as condições em que se estruturava o mercado de formação universitária no período da pesquisa, notadamente nessas duas cidades, não propiciavam necessariamente a inclusão desses jovens no mercado de trabalho qualificado, nas trocas sociais, espirituais e culturais mais valorizadas, nos termos de Wanderley (2006).

O estudo revelou, ademais, uma clara diferença nas formas como homens e mulheres vivenciavam o desemprego, prevalecendo a divisão de 


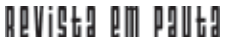

\} DESEMPREGO DE JOVENS AMAPAENSES - CORREIO, M. A. N.; CORREIO, S. R. S. \}

DOI: $10.12957 /$ REP.2016.27865

papéis atribuídos de acordo com o sexo e a raça/etnia. Entre os homens, $77,8 \%$ declararam-se negros (pretos e pardos) e 22,2\%, brancos. Entre as mulheres, 63,6\% declararam-se negras, contra 36,4\% brancas. A soma de todos os jovens que se autoidentificaram como negros foi de $70 \%$. As situações enfrentadas pelas mulheres pretas e pardas eram particularmente adversas. A maioria desenvolvia atividades em ocupações mais precárias, se comparadas às de outros jovens, o que remetia à consubstancialidade entre classe, gênero, raça/etnia e geração, para a qual os estudos feministas têm chamado a atenção.

Sem compreender como se estrutura o mundo do trabalho nos tempos atuais, os jovens atribuíam a si próprios a responsabilidade e a culpa pelo desemprego, e repetiam o discurso da empregabilidade e do empreendedorismo. Nesse sentido, ingressavam em cursos de curta duração que julgavam poder auxiliá-los em uma inserção mais rápida no mercado de trabalho. Novamente a ideologia do esforço próprio e da qualificação profissional alimentava a ideologia da educação como solução para o desemprego estrutural.

\section{Considerações finais}

Conforme já mencionado, ProUni e Fies ilustram bem o que foi a política econômica em curso no Brasil em 2014. Tratavam-se de programas que tinham como proposta de base a articulação entre o crescimento econômico e o fortalecimento de políticas sociais para mulheres, negros, deficientes e jovens.

Sem pretender generalizar o estudo de caso realizado nas cidades de Macapá e Santana, mas visando contribuir com reflexões críticas sobre as contradições do mundo do trabalho, sobre as políticas públicas e, fundamentalmente, as lutas pela expansão da educação pública com qualidade, conclui-se que a realidade analisada corrobora a hipótese de que os programas governamentais, a despeito de ter possibilitado o acesso à formação superior para um significativo número de jovens, não responderam às suas expectativas e às de suas famílias.

Um achado expressivo da pesquisa diz respeito ao modo como os jovens ingressam na formação universitária. As trajetórias educacionais nem sempre são marcadas pela previsibilidade e pelo planejamento. A inserção em curso de formação superior não parece ser uma opção, mas uma necessidade, pautada na crença de que ela pode diminuir o caminho para o mercado de trabalho. Em contrapartida, os cursos não estão, em sua maioria, relacionados com as demandas do mercado, mas sim à possibilidade de transformar a educação em mercadoria que deve ser vendida.

As transformações no mundo do trabalho e a acumulação flexível transformaram parte da classe trabalhadora em desempregados, 


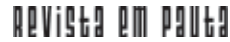

\} DESEMPREGO DE JOVENS AMAPAENSES - CORREIO, M. A. N.; CORREIO, S. R. S. \}

DOI: $10.12957 /$ REP.2016.27865

precarizados, terceirizados, colocando os trabalhadores no mundo da instabilidade e incerteza. O desemprego e a precarização deixam de atingir segmentos específicos da sociedade para se generalizar, não havendo nenhum segmento imune a esse processo.

Há um aumento expressivo de desemprego e precarização entre segmentos até então protegidos pelo mercado de trabalho, como os jovens que possuem formação superior, o que pode comprovar que o aumento do desemprego é uma questão estrutural e histórica, relativizando o argumento da educação como solução para o problema. O discurso ideológico a respeito da educação superior, que prega a possibilidade de entrada rápida e fácil no mercado de trabalho, é um dos fatores que contribui para o aumento de matrículas em faculdades, sobretudo as particulares. Os dados mostram que, contrariando as expectativas, esse processo não implica aumento de postos de trabalho para os jovens recém-formados. Diante do exposto, resta a esperança de que a compreensão crítica dessa contradição leve os jovens a processos de sedição relevantes contra a barbárie social e política. 


\section{Referências}

ABRAMO, H. W. Condição juvenil no Brasil contemporâneo. In: ABRAMO, H. W.; BRANCO, P. P. M. Retratos da juventude brasileira. São Paulo: Perseu Abramo, 2008.

ALVES, G. O novo e (precário) mundo do trabalho. Reestruturação produtiva e crise do sindicalismo. São Paulo: Boitempo, 2010.

ANTUNES, R. Adeus ao trabalho? Ensaios sobre as metamorfoses e centralidade do mundo do trabalho. São Paulo: Cortez, 2000.

. Os sentidos do trabalho. Ensaios sobre a afirmação e a negação do trabalho. São Paulo: Boitempo, 2006.

A nova morfologia do trabalho e suas principais tendências. In: ANTUNES, R. (Org.). Riqueza e miséria do trabalho no Brasil II. São Paulo: Boitempo, 2013.

BEHRING, E. Brasil em contra-reforma. Desestruturação do Estado e perda de direitos. São Paulo: Cortez, 2003.

BORGES, A. Mercado de trabalho: mais uma década de precarização. In. DRUCK, G.; FRANCO, T. A perda da razão do trabalho: terceirização e precarização. São Paulo: Boitempo, 2009.

BOURDIEU, P. Escritos de educação. Petrópolis: Vozes, 2007.

BRASIL. Constituição (1988). Constituição da República Federativa do Brasil. Brasília, DF: Senado Federal: Centro Gráfico, 1988.

Lei n. 12.852 de 5 de agosto de 2013. Estatuto da Juventude. Brasília: Casa Civil, 2013.

INEP. Resultados do censo da educação superior. Inep, 2013. Disponível em: <download.inep.gov.br/educação_superior/censo_superior/apresenta ção/2014/coletiva_censo_superior_2013.pdf.>. Acesso em: 7 dez. 2014.

CHAUÍ, M. Escritos sobre a universidade. São Paulo: Unesp, 2001.

CORTI, Ana Paula; SOUZA, Raquel. Diálogos com o mundo juvenil: subsídios para educadores. São Paulo: Ação Educativa, 2004.

DRUCK, G. Flexibilização e precarização: formas contemporâneas de dominação do trabalho. Dossiê. Caderno CRH, Salvador, jul./dez., 2002.

FRIGOTTO, G. Juventude, trabalho e educação no Brasil: perplexidade, desafios e perspectiva. In: NOVAES, R.; VANNUCHI, P. Juventude e sociedade: trabalho, educação, cultura e participação. São Paulo: Fundação Perseu Abramo, 2004.

GENTILI, P. (Org.). Universidades na penumbra. Neoliberalismo e reestruturação universitária. São Paulo: Cortez, 2001. 


\section{hevistg aाm pguttg}

\} DESEMPREGO DE JOVENS AMAPAENSES - CORREIO, M. A. N.; CORREIO, S. R. S. \}

DOI: $10.12957 /$ REP.2016.27865

IBGE. INSTITUTO BRASILEIRO DE GEOGRAFIA E ESTATÍSTICA. Cidades. 2014. Disponível em: <http://www.cidades.ibge.gov.br/xtras/home. php>. Acesso em: 1 set. 2015.

LEHER, R. Projetos e modelos de autonomia e privatização de universidades públicas. In: GENTILI, P. (Org.). Universidades na penumbra. Neoliberalismo e reestruturação universitária. São Paulo: Cortez, 2001.

MARTÍN-BARBERO, J. A mudança na percepção da juventude: sociabilidades, tecnicidades e subjetividades entre os jovens. In: BORELLI, S. H. S.; FREIRE FILHO, J. Culturas juvenis no século XXI. São Paulo: Educ, 2008. MDS. MINISTÉRIO DO DESENVOLVIMENTO SOCIAL. Relatório de informações sociais. Panorama municipal segundo o censo demográfico 2010. [2012]. Disponível em: <www.aplicações.mds.gov.br/sagi/ri/carrega _pdf.pdf? rel=panorama_municipal>. Acesso em: 5 fev. 2015.

NASCIMENTO, M. A. C.; NEVES, S. R. S; BARACHO, G. A. S. Percepções dos beneficiários sobre o Programa de Transferência de Renda e Bolsa Família no Pará e Renda para Viver melhor no Amapá. In: NASCIMENTO, M. A. C (org.). Tempos de Bolsa: estudos sobre Programas de Transferência de Renda. Campinas: papel social, 2015. p. 148-186.

POCHMANN, M. Desempregados do Brasil. In: ANTUNES, R. (Org.). Riqueza e miséria do trabalho do Brasil. São Paulo: Boitempo, 2006.

OIT. ORGANIZAÇÃO INTERNACIONAL DO TRABALHO. Relatório tendências mundiais do emprego em 2013. Brasil: OIT, 2013a. Disponível em: <www.oitbrasil.org.br/sites/default>. Acesso em: jan. 2014.

- Relatório tendências mundiais do emprego juvenil: uma geração em perigo. Brasil: OIT, 2013b. Disponível em: <www.oitbrasil.org.br/sites/ default>. Acesso em: 24 mar. 2015.

. Relatório tendências mundiais do emprego em 2013. Brasil: OIT, 2014. Disponível em: <www.oitbrasil.org.br/sites/default>. Acesso em: 12 dez. 2014.

SANTOS, M. Por uma outra globalização. Do pensamento único à consciência universal. Rio de Janeiro: Record, 2011.

SILVA JR., J.; SGUISSARDI, V. Novas faces da educação superior no Brasil. São Paulo: Cortez, 2001.

THÉBAUD-MONY, A.; DRUCK, G. Terceirização: a erosão dos direitos dos trabalhadores na França e no Brasil. In: DRUCK, G.; FRANCO, T. A perda da razão do trabalho: terceirização e precarização. São Paulo: Boitempo, 2007.

TRINDADE, H. As metáforas da crise: da "universidade em ruínas" às "universidades na penumbra" na América Latina. In: GENTILI, P. (Org.). Univer- 


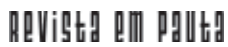

\} DESEMPREGO DE JOVENS AMAPAENSES - CORREIO, M. A. N.; CORREIO, S. R. S. \}

DOI: $10.12957 /$ REP.2016.27865

sidades na penumbra. Neoliberalismo e reestruturação universitária. São Paulo: Cortez, 2001.

WANDERLEY, M. B. Refletindo sobre a noção de exclusão. In. SAWAIA, B. (Org.). As artimanhas da exclusão. Petrópolis: Vozes, 2006.

Recebido em 15 de abril de 2016.

Aprovado para publicação em 17 de novembro de 2016. DOI: $10.12957 /$ rep.2016.27865

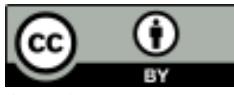

A Revista Em Pauta: Teoria Social e Realidade Contemporânea está licenciada com uma Licença Creative Commons Atribuição 4.0 Internacional. 